\title{
Towards Transformation: The Power of Phonetic Symbols Embedded in the Multimedia Learning Management System
}

\author{
Fei Ping Por \\ School of Educational Studies, Universiti Sains Malaysia \\ Minden 11800, Penang, Malaysia \\ Tel: 60-12-423-3805 E-mail: christinepor@gmail.com \\ Soon Fook Fong (Corresponding author) \\ School of Educational Studies, Universiti Sains Malaysia \\ Minden 11800, Penang, Malaysia \\ Tel: 60-4-653-2968Ｅ-mail: sffong05@gmail.com
}

\begin{abstract}
The conventional way of using letter-to-sound approach to acquire English pronunciation competence is limited to simple and regular English words in elementary level. This limitation signifies the potentialities of phonetic symbols that are applicable to the pronunciation of all the words of human languages. The researchers are exploring the innovative use of phonetic symbols within the multimedia based English Pronunciation Learning Management System. The dynamic interactive learning system bears practical value to help novice users of the system become active and independent English pronunciation learners. The learners will be expected to benefit from this innovative approach to substantially improve their pronunciation competence. The proposed Multimedia Pronunciation Learning Management System (MPLMS) marks a radical transformation of pronunciation learning.
\end{abstract}

Keywords: Phonetic symbols, Pronunciation, Multimedia, Learning Management System, Non-native English speaking

\section{Introduction}

The globalisation trend has further reinforced the position of English as the lingua franca. English is the mother tongue of more than 350 million people in the world and it is used by 1,000-1,500 million non-native speakers (Katamba, 2005) daily for communication. In the European Union, English (34\%) is the most widely known language (Special Eurobarometer 237, September 2005). For instance, Italy has made learning a foreign language compulsory from the first year of primary education with English being the most commonly taught language (Neri, Mich, Gerosa, \& Giuliani, 2008). Study done by Kim (2003) also concluded that English is the most popular choice of foreign language in South East Asia.

Being able to communicate in English is relatively indispensable in today's world in the light of the increased people's mobility, joint study programmes, commercial networks, information technology, and many more. Unfortunately, the non-native English speakers with different cultural background and native languages experience pronunciation difficulties. Rivers (1968) contended the difficulty of non-native speakers is barely due to their lack of vocabulary and grammar, but primarily because of the sounds they produce are incorrect, the intonation and the pitch seem strange. Celce-Murcia (1987) also commented that if a non-native speaker's pronunciation is underperformed, he or she will not be able to communicate orally even though the mastery of vocabulary and grammar is good. Many errors produced by the non-native speakers can be attributed to unconscious interference phenomena from their native languages (Flege, 1995). The influence of native language can be so overwhelming that the learners may not be aware of the deviations subconsciously.

An illustration by Carson (2009) who has taught English as a foreign language reported that people from Chinese speaking background have problem in pronouncing the letter ' $r$ '. They may instead produce the sound as ' 1 ', thus leading to "flied lice" rather than "fried rice". This is similar for Arabic speaking people, who pronounce 'p' as 'b', thus "Paul's bath" becomes "Ball's path". And for those from Spanish or Indian speaking family, the sound of 'b' is like ' $v$ ', and German speaking people will mix up ' $v$ ' with 'w' (Carson, February 6, 2009). With his vast teaching experience in western Malaysia, Hart (1969) highlighted that Malaysians are confused in distinguishing English tense and lax vowels, such as /i:/ and /I/, / :/ and /p/, /u:/ and /o/. Listeners, especially native English speakers usually misunderstand when the following words are pronounced by Malaysians: leave and live; caught and cot, pool and pull (Hart, 1969). With the interference of Malay language, Malaysians are also inclined to pronounce English words based on the spelling, for example, major is incorrectly pronounced as / $\mathrm{ma} \mathrm{d} 3 \mathrm{p} /$. This is owing to 
Malay language is regarded as a phonetic language whereby the sound of a word can be produced by looking at the written word as there is a direct relationship between the spelling and the sound (Essberger, 2001). English, however, is a language without having a pure phonemic orthography (Katamba, 2005). Hence, to speak the new language intelligibly, the non-native speakers have to establish "new ways of hearing, new ways of using speech organs and new speech habits" (Connor, 1980, p.3).

In addressing the issues, the researchers contend using Multimedia Pronunciation Learning Management System (MPLMS) will be expected to help correct pronunciation across all the non-native English speaking countries.

\section{Limitations of Traditional Way of Teaching}

Undeniably, the most important factor affecting student learning is the teacher (Wright, Horn, \& Sanders, 1997). The interactivity and personal touch in the human teacher-student relationships enhance students' performance. However, the capacity of a teacher is limited by accessibility. For instance, a teacher can only interact face-to-face effectively with the maximum of 20 students per class (Ellis, 1984) at one time in one location. For the MPLMS, it can be accessed any time simultaneously by millions of people in various parts of the world. Furthermore, the sound recordings in the pronunciation programme are infinitely repeatable with reliable quality in the sense of being the same every time (Pennington, 1999). This feature helps learners increase the precision of articulation in a language, specifically English in this study. In contrast, a teacher can only repeat the pronunciation of a word for limited times and with varied quality each time.

Looking at the high teacher-student ratio in the classroom, it is unrealistic for teachers to provide real-time individual feedback on the utterance of each student in detail. It is even impossible for teachers to analyze the sounds of every student according to places and manners of articulation.

In addressing the various limitations of traditional way of teaching, the MPLMS emerges as a timely and useful tool to provide personalized one-to-one guidance to the non-native English speakers in improving their pronunciation.

\section{Multimedia Pronunciation Learning Management System (MPLMS)}

In the light of the limitations of human teachers, the usage of the MPLMS is expected to be an effective complementary tool. Not only it provides high quality individualized instruction and interaction even with students working en masse, but also it is effort-saving to the human teachers and labour-saving to the students. The MPLMS ensures consistency in delivery and evaluation since each user sees the same materials and is evaluated through the common pre-test and post-test by the same system (Brown \& Johnson, 2007). As in the context of non-native English speaking environment, exposure to the interaction with native English speakers is rare. The intervention of MPLMS increases the contact with standard English pronunciation and, therefore, offers considerable promise to improve the pronunciation competence of non-native English speakers.

The MPLMS is a Learning Management System implemented in online website portal, and hence it is accessible through the Internet anytime, anywhere by unlimited number of people all over the world synchronously and asynchronously for quality sustainable learning. The online resources and databases can be maintained, modified, edited and upgraded easily according to the current needs. Users will always have the latest information. The MPLMS turns the web to a dynamic user-centric collection of consistent and timely information (Strauss, 2002) in the learning of pronunciation. It is also able to manage and keep users' progress, activity and performance. This is a breakthrough compared to the existing learning software in the market where the learning contents and interactive practices are presented in $\mathrm{CD}$ format in which information is hardly revised and the progress of individual user is difficult to be tracked in detail. For further enhancement, the MPLMS allows instructors and/or parents to review the learning records and analyse the record data to determine the strengths and areas needed for improvement (Brown \& Johnson, 2007).

The MPLMS is navigable, learner-centric, dynamic and sustainable. By clicking on the links of every screen, the learners are able to select the lessons they want to explore. The system encourages self-paced, self-enhanced and self-monitored learning. It guides the learners systematically but at the same time gives the learners freedom to learn at their own pace. They can start and stop the lessons as well as review the lessons at a pace efficient to them. This provides opportunities for autonomous practice. The learners make the decisions about when, where, what and how quickly to learn. Control of the learning process encourages active learning and is highly motivating for the learners (Sullivan, 2001). The learners will also learn to be more independent in creating their own learning steps. This will definitely help the slow learners from being frustrated and the fast learners from getting bored (Nur Aini, Omar, \& Chow, 2002). Furthermore, the system is designed by allowing the learners to make mistakes and keep on practising for improvement at their own pace without having to compete with others. Under formal classroom setting, learners are reluctant to practise their pronunciation in front of others as the mistakes made causing them to feel embarrassed 
and intimidated. This situation hinders learners from practising and improving, and they gradually become more and more passive. In this regard, the MPLMS has the capacity to overcome the problems and makes learning pronunciation effective and yet a fun experience. With the innovative use of graphics, animations, video and audio displaying, learners will be full of interest and their learning enthusiasm will be enhanced.

\section{The Study}

The efficacy of phonetic symbols incorporated into multimedia-based Pronunciation Learning Management System on the acquisition of English pronunciation among the non-native English speakers has not been extensively investigated (Qiu \& Hewitt, 2005). In order to examine the effectiveness, the following frameworks are designed (see Figures 1-3).

This study is to be conducted by developing two modes of interactive multimedia presentation, namely (i) Text + Sound (TS) and (ii) Text + Sound + Phonetic Symbols (TSPS). TS mode and TSPS mode are similar in terms of content, text presentation and sound production. However, phonetic symbols are incorporated into TSPS mode. The phonetic symbols are to be displayed simultaneously on the same screen of the English word.

The objective of this study is to investigate whether phonetic symbols would be an important feature incorporated in the MPLMS to attain correct pronunciation by non-native English speakers.

The project is expected to answer the following questions:

(i) Are Phonetic Symbols effective in helping non-native English speakers acquire correct pronunciation?

(ii) Does the Text+Sound+Phonetic Symbols (TSPS) group score significantly higher on a pronunciation competence posttest than the Text+Sound (TS) group?

\section{Aural-Oral Approach and Pronunciation}

Learning to pronounce a word, to speak a new language, it depends primarily on hearing. By hearing the sound, the learners imitate and reproduce the articulation. One or two vague hearings of the pronunciation of a word is insufficient to ensure good performance. Repetitive aural-oral drills is needed to build up a store of sound-memory (Connor, 1980) which forms a library for the learners. The learners listen closely to the model pronunciation of a word repeatedly, and learn to utter the word. They may then record their own pronunciation. Using the compare feature in the MPLMS, their pronunciation is comparable with the model pronunciation. They listen attentively to both pronunciations and take note of the deviations. With this practice, the MPLMS supports ear recognition trainings and oral drillings which enables learners to hear and remember, recall and reproduce.

\section{Letter-to-Sound Approach and Pronunciation}

People nowadays invented many easy ways to make English words pronounced based on its letters. However, "letters and sounds must never be mixed up" as emphasized by Connor (1980). Connor (1980) further explained that "letters are written, but sounds are spoken. It is very useful to have written letters to remind us of corresponding sounds, but they cannot make us pronounce sounds; they simply remind us" (p. 7).

English words are pronounced in irregular ways so it is imprudent to make letter-to-sound connections. For instance, for homophones, the words have exactly the same pronunciation but have different spellings, such as dye and die are spelled differently but they carry the same pronunciation of /da I/. On the other hand, for homographs, the spelling of the words is exactly identical but they have different meanings and sometimes different pronunciation, such as wind is pronounced as /wind/ to denote air that moves quickly but it is pronounced as /wa Ind/ meaning to wrap or twist something around ("Oxford Advanced Learner's Dictionary 7th edition," 2005). Besides, the immense number of silent letters contained in English words presents differing degrees of difficulty to pronunciation. If literally refer to the letters, all of them should be pronounced. In actual fact, however, the underlined bold letters in the following words are not pronounced: knee /ni /, wrinkle / $\mathrm{r}$ I $\mathrm{jkl} /$, listen / 1 1 sn/, doubt /daut/, and the like. Furthermore, for words like holy / hooli/ and honey / h $\wedge$ ni/, the letter 'o' represents different sounds of /oo/ and $/ \Lambda /$. Similarly, the letter string (four-letter phonograms) 'ough', when it is combined with different consonants, the pronunciation varies. For example, bough /bav/, cough $/ \mathrm{kpf} /$, dough $/ \mathrm{d} ə \mathrm{v} /$, tough $/ \mathrm{t} \Lambda \mathrm{f} /$, and so on. There are 26 letters in the English alphabet but they stand for at least 44 different sounds (Sousa, 2005). According to Sousa (2005), there are more than 1,100 different ways of spellings for 44 discrete sounds in English, which is more compared to other languages, such as Italian, Spanish and French. In brief, the inconsistencies between written letters and spoken sounds in English cause pronunciation hardly to be learned from the letter itself. To understand the reasons of inconsistencies, the etymology of each English word needs to be studied further. For some words, the pronunciation has evolved over time but the spelling remains unchanged. Moreover, many English words are derived from Latin and Greek, and the original spellings are kept though the pronunciation in English differs. Some English words are the results of the fusion of different languages and dialects (Gelderen, 2006). In light of the word history and its 
borrowing language, there is no absolute direct relationship between letter and sound in English.

Although there may be pronunciation rules formulated, always there are long lists of accompanying exceptions to be remembered. For instance, when the letter ' $\mathrm{g}$ ' is placed before the letters ' $\mathrm{e}$ ', ' $\mathrm{i}$ ', or ' $\mathrm{y}$ ', it is usually pronounced as soft /d3/ sound: gem /dzem/, ginger / d3 Ind3ə(r)/, gymnasium /d3ım ne Iziəm/, except get/get/, hunger

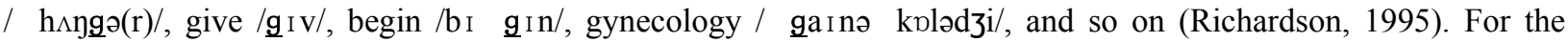
learners of English pronunciation, they will be confused to figure out when they should pronounce ' $\mathrm{g}$ ' as $/ \mathrm{d} 3 /$ or $/ \mathrm{g} /$, or should they just memorize all the exceptions? Here is only one example of the pronunciation rules. How about many other letters which do not follow the standard pronunciation rules?

\section{Respellings and Pronunciation}

People also invented respelling systems to spell out the pronunciations of words. There are basically two types of respelling systems: phonemic and non-phonemic respellings. Phonemic respelling is actually "a phonemic transcription using the ordinary letters of the alphabet" (Fraser, 1997, p. 184), such as phoneme is indicated as I fō- nēml; whereas, for non-phonemic respelling, it is "a word's pronunciation represented according to the ordinary spelling rules of English" (Galescu, 2009, p. 130), such as phoneme is indicated as \foh-neem\.

Our fast-paced society tends to adopt this type of straightforward pronunciation respellings, but this system can only represent imprecise and ambiguous terms to describe a sound. For example, the same vowel/e I/ for phase /fe Iz/ and vague /verg/ is represented in two different ways: $\boldsymbol{a}$ and $\boldsymbol{a} \boldsymbol{i}$ for $\backslash$ faze $\backslash$ and $\mid$ vaig $\mid$ respectively (Fraser, 1997). The sound for tomorrow can also be represented in either $\backslash$ tuh-mawr-oh $\backslash$ or $\backslash$ tə- mär-( )ō $\backslash$ ("Dictionary.com," 2010; "Merriam-Webster Online Dictionary," 2010). The lack of systematicity in this system is most often criticised and has shaken its global recognition. This non-standard informal way of respelling system leads to inability to distinguish the exact individual sounds. Furthermore, for non-native speakers of English, respelling is less meaningful to them owing to the interference of their own mother tongue which has different spelling conventions (Fraser, 1997). To them, the respelling system is perceived as 'odd combination of letters' (for example, pruh-nun-see-AY-shuhn) that produce unusual sounds. Though, the background knowledge of the language lies within native English speakers suffices to map the corresponding sounds, the usage is only limited in few dictionaries, such as Merriam-Webster Online and Dictionary.com. Therefore, in the context of non-native English speaking environment, respelling is less appropriate and unpopular.

\section{IPA (International Phonetic Alphabet) symbols and Pronunciation}

The first version of the International Phonetic Alphabet (IPA) symbols applicable to all languages was successfully devised in 1888 (Pullum \& Ladusaw, 1996). The chief principle of the IPA in providing one unique symbol for one discrete sound and the symbol is used consistently for all languages (The International Phonetic Association, 2003) is meant to be easier for the pronunciation learners of non-native English speaking background to understand. The IPA reduces the ambiguities of pronunciation learning as there is no overlapping of sounds.

Looking at the non-native English speaking context is in favour of the IPA, the MPLMS incorporates phonetic symbols in the teaching and learning interface.In fact, the long existed IPA symbols are adopted in reputable dictionaries, such as Oxford Advanced Learner's Dictionary, Oxford Dictionary of Pronunciation, Cambridge International Dictionary of English, Longman Pronunciation Dictionary, Collins English Dictionary, and many more, but they are not prevailing in use. The application of the symbols is not emphasized in schools and the symbols seem to be sidelined in English language teaching. Many are aware of its presence but are unclear of its usage. The intervention of the MPLMS is to optimize this universally agreed system of notation for sounds to achieve great capacity of pronunciation improvement among non-native English speakers.

As the stakeholders of the MPLMS are non-native speakers with no specific knowledge in linguistics, the knowledge of phonetics delivered through the MPLMS is basic and simple, and with the emphasis of mastery-based. The objective of the MPLMS is to equip the users with phonetic symbols which include vowels and consonants and the sounds, without requiring the acquisition of technical knowledge of detailed description of speech sounds, for example, place of articulation, manner of articulation, voicing and airstream mechanism. After the novice pronunciation learners master the basic concept, they may move on to match the phonetic symbols with the audio pronunciation of a word. Phonetic transcription refers to the use of phonetic symbols in sequence to represent the speech sound of a word (The International Phonetic Association, 2003). With this ongoing practice in building mental pronunciation library, the users of the MPLMS will ultimately become active and independent learners. It is expected that the increased use of the MPLMS would augment their skills. By mastering the concept of phonetic symbols, the learners are able to discern whether the audio pronunciation is correct, able to detect the sound variations, and able to pronounce the words even when the recordings are unclear or faulty. At anytime and anywhere, when they refer to the phonetic symbols in the dictionaries (whether in the form of digital, printed or the 
built-in dictionary in mobile phone), they are able to pronounce the new words.

Although there are more than a hundred of symbols in the IPA, it is unnecessary to learn all the symbols and their corresponding sounds by the pronunciation learners of English. The IPA symbols are in fact designed for all the languages in the world, and hence the number of symbols will be increased, or modified, or even removed to accommodate needs. As for the goal of this MPLMS is to equip the non-native speakers to pronounce English words correctly without so much emphasis on precision, the learners are not required to master the whole complete set of the IPA which indicate the changes of sounds in great detail. For instance, diacritics (the small letter-shaped symbols, for example, $\left.\left.\left[{ }^{[}\right],[]\right],{ }^{\boldsymbol{\gamma}}\right],[\mathrm{]}]$ ) that deal with the distinctions of sound quality of different aspects of phonation, especially for cross-language comparison (The International Phonetic Association, 2003) are inessential in this context. To learn the phonemes of one language, the mastery of regular symbols is sufficient, and this makes the learning of phonetic symbols less sophisticated and more appealing.

\section{Conclusion}

The intervention of MPLMS has maximized the potentialities of phonetic symbols which have been existed over a century but yet being underused previously. Taking advantages of phonetic symbols, the learners are able to receive individual and instantaneous feedback by comparing the sounds of model pronunciation and their pronunciation, and approximate the pronunciations with the displayed phonetic symbols. Through this provision of personalised and immediate feedback, learners are able to self-assess their mispronunciation and do quick repair. Therefore, the MPLMS integrated innovatively with phonetic symbols is beneficial to learners by allowing them to practise their pronunciation infinite times independently and actively until they are satisfied with the newly-acquired sounds without total dependence on sound imitation via aural-oral drills. On this basis, the inventive MPLMS can help improve learners' pronunciation competence and build their confidence while developing skills in sound discrimination.

The MPLMS has also increased learners' accessibility to their own pronunciation learning without needing to wait for teacher's instructions. They decide the learning contents, the learning pace and the learning location. This private and stress-free environment enhances learners' motivation and effort to work on their pronunciation.

Clearly, more empirical research is needed to investigate the pedagogical effects of phonetic symbols on the pronunciation performance of the learners so that the usage of the MPLMS will continue to expand to all non-native English speaking countries irrespective of cultural background and native languages. Nonetheless, it is believed that the empirical study to be conducted will give positive indications that phonetic symbols would be an excellent feature to improve the pronunciation competency among non-native English speakers.

\section{References}

Brown, A., \& Johnson, J. (2007). Five Advantages of Using a Learning Management System. Retrieved October 22, 2010 , from: http://microburstlearning.com/articles/Five\%20Advantages\%20of\%20Using\%20a\%20Learning\%20Management\%2 0System.pdf

Carson, V. (2009, February 6). Common mistakes. The Star Online. Retrieved May 20, 2010, from: http://thestar.com.my/lifestyle/story.asp?file=/2009/2/6/lifefocus/3001765\&sec=lifefocus

Celce-Murcia, M. (1987). Teaching Pronunciation As Communication. In: J. Morley (Ed.) Current Perspectives on Pronunciation TESOL, 1-12.

Connor, J. D. O. (1980). Better English Pronunciation (2nd ed.). Cambridge: Cambridge University Press.

Dictionary.com. (2010). Retrieved September 14, 2010: http://dictionary.reference.com/browse/tomorrow

Ellis, T. I. (1984). Class Size. ERIC Clearinghouse on Educational Management: ERIC Digest, 11. ED 259454

Essberger, J. (2001). English is not Phonetic. Retrieved September 3, 2010, from http://www.englishclub.com/esl-articles/200104.htm

Flege, J. E. (1995). Second-language Speech Learning: Findings and Problems In W. Strange (Ed.), Speech Perception and Linguistic Experience: Theoretical and Methodological Issues (pp. 233-273). Timonium, MD: York Press.

Fraser, H. (1997). Dictionary Pronunciation Guides for English. International Journal of Lexicography, 10(3), 181-208.

Galescu, L. (2009). Extending Pronunciation Lexicons via Non-phonemic Respellings. Paper presented at the Proceedings of NAACL HLT, pages 129-132, Boulder, Colorado. 
Gelderen, E. v. (2006). A History of the English Language. Amsterdam: John Benjamins Publishing Company.

Hart, D. C. (1969). Some English Pronunciation Difficulties in Malaysia. ELT Journal, XXIII(3), 270-273.

Katamba, F. (2005). English Words: Structure, History, Usage (Second Edition). Oxon: Routledge Taylor \& Francis Group.

Kim, L. S. (2003). Multiple Identities in a Multicultural World: A Malaysian Perspective Journal of Language, Identity, and Education, 2(3), 137-158.

Merriam-Webster Online Dictionary. (2010). Retrieved September 14, 2010, from: http://www.merriam-webster.com/dictionary/tomorrow

Neri, A., Mich, O., Gerosa, M., \& Giuliani, D. (2008). The Effectiveness of Computer Assisted Pronunciation Training for Foreign Language Learning by Children. Computer Assisted Language Learning, 21(5), 393-408.

Oxford Advanced Learner's Dictionary 7th edition. (2005). New York: Oxford University Press.

Pennington, M. C. (1999). Computer-Aided Pronunciation Pedagogy: Promise, Limitations, Directions. Computer Assisted Language Learning, 15(5), 427-440.

Pullum, G. K., \& Ladusaw, W. A. (1996). Phonetic Symbol Guide (2nd Edition ed.). Chicago: The University of Chicago Press.

Qiu, M., \& Hewitt, J. (2005). Integrating Computer-based Multimedia Instructional design into Teaching English Phonetic Symbols. Paper presented at the Proceedings of World Conference on Educational Multimedia, Hypermedia and Telecommunications 2005, Chesapeake, VA.

Richardson, C. M. (1995). The Alphabet Code \& How It Works. Retrieved September 12, 2010, from http://www.donpotter.net/PDF/Alphabet\%20Code\%20-\%20Loring\%20Sequence.pdf

Rivers, W. M. (1968). Teaching Foreign Language Skills (2nd ed.). Chicago, IL: Chicago University Press.

Sousa, D. A. (2005). How the Brain Learns to Read. California: Corwin Press.

Special Eurobarometer 237. (September 2005). Europeans and Languages European Commission, Directorate-General Press and Communication, Opinion Polls.

Strauss, H. (2002). Chapter 4: All About Web Portals: A Home Page Doth Not a Portal Make. In R. N. Katz \& Associates (Eds.), Web Portals and Higher Education: Technologies to Make IT Personal (pp.33-40). San Francisco: Jossey-Bass Inc.

Sullivan, R. (2001). Alternative Learning Methods: Self-Paced Learning (Part 3 of 5). JHPIEGO TrainerNews (November 2001).

The International Phonetic Association. (2003). Handbook of the International Phonetic Association: a guide to the use of the International Phonetic Alphabet. UK: Cambridge University Press.

Wright, S. P., Horn, S. P., \& Sanders, W. L. (1997). Teacher and Classroom Context Effects on Student Achievement: Implications for Teacher Evaluation. Journal of Personnel Evaluation in Education 11, 57-67.

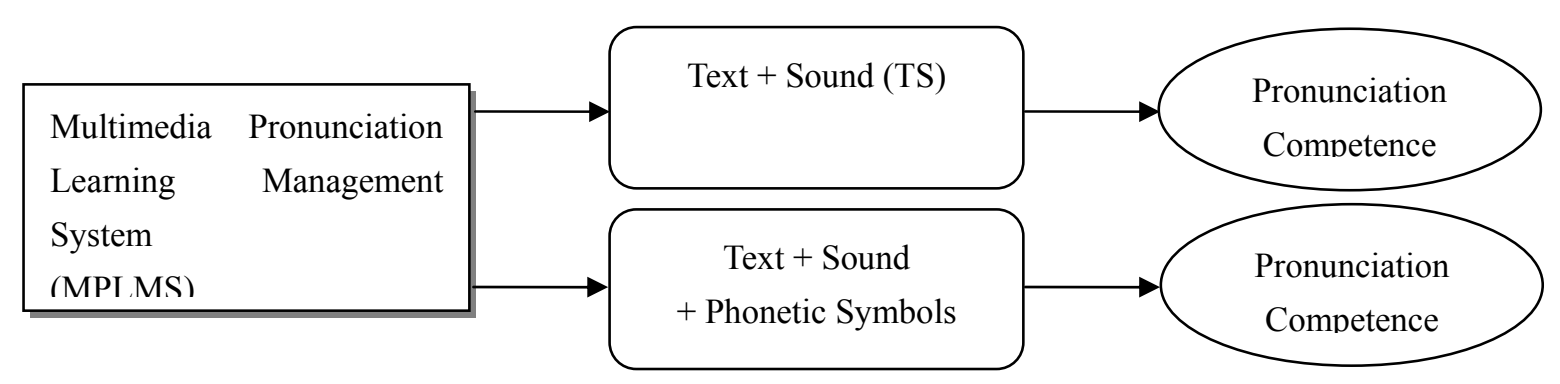

Figure 1. Research Framework 


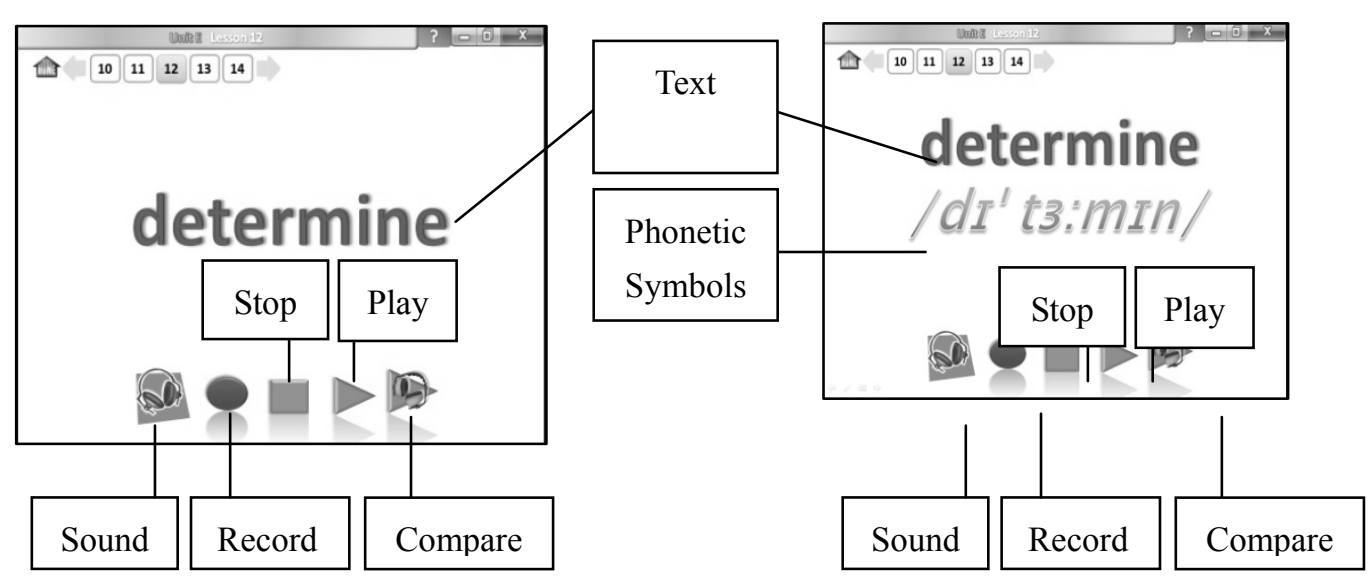

Figure 2. Screenshot of 'TS' Presentation

Figure 3. Screenshot of 'TSPS' Presentation 